\title{
Investigando o processo de adoção no Brasil e o perfil dos adotantes*
}

\author{
Luana Andrade Silva ${ }^{I}$ \\ Danielisson Paulo de Mesquita ${ }^{2}$ \\ Beatriz Girão Enes Carvalho
}

Universidade de Uberaba

O processo de adoção no Brasil apresenta dificuldades, facilidades e diferença no perfil dos adotantes. $\mathrm{O}$ perfil do adotante brasileiro é de: casais brancos, inférteis, idade entre 30 e 40 anos, classe média-baixa e $3^{\circ}$ grau completo. As facilidades são: permissão de estágio de convivência com o adotado antes de o processo concluir-se; grupos de apoio aos candidatos; mudanças na lei favorecendo mais o bem-estar do adotado; cadastro nacional online; licença-maternidade e ausência de prioridades na fila de espera dos adotantes. As dificuldades são: pouca pesquisa científica; cadastro não atualizado em todo o Brasil; preconceitos/mitos; desproporção entre número de adotantes e adotivos; adoção por homossexuais; adoção de crianças com idade acima de 3 anos e burocracia no processo. Para alcançar os objetivos deste trabalho, utilizou-se de pesquisa bibliográfica com abordagem qualitativa, observando um tema amplo e com várias mudanças nas normas de adoção no decorrer da História.
The process of adoption in Brazil presents positive aspects, some difficulties and differences in the profiles of the adoptees. The profiles of Brazilian adopter are: white couples, unable to conceive, between the ages of 30 and 40 years old, working class with high school diploma. The positive aspects are: permission for the adoptee to reside with the adopter before the adoption process is concluded; support groups are offered to the candidates; changes in policy that benefit the adoptee were made recently; online access to national enrollment; maternity leave and no special treatment given to those in the wait list. The difficulties are: Little scientific research regarding adoption; lack of updates in enrollment files; prejudices and myths; disproportionate number of adoptees and adopters, adoptions by homosexuals; adoption of children older than 3 years old and long bureaucratic process. In order to achieve the objectives of this study, bibliographic research was utilized, enclosing qualitative, while giving insight to an ample subject, which endured many changes in its adoption rules throughout history.

\footnotetext{
*Investigating the process of adoption in Brazil and the adopter's profile

1 Graduada em Terapia Ocupacional pela Universidade de Uberaba/MG. Endereço para correspondência: Rua Silvio de Castro Cunha, 198, Alvorada, Uberaba, MG, $38061-530$ (luana.to.2009@gmail.com).

${ }^{2}$ Especialista docente do curso de Terapia Ocupacional da Universidade de Uberaba/MG.

${ }^{3}$ Mestre docente do curso de Terapia Ocupacional da Universidade de Uberaba/MG.
} 
Palavras-chave: Adoção - Adotantes

- Crianças e adolescentes - Brasil
Keywords: Adoption - Adopter's -

Children and adolescents - Brazil

\section{Introdução}

\section{Breve histórico da adoção}

Q egundo Weber (1998), a adoção foi reconhecida primeiramente pelo Código de Hamurabi (1728-1686AC), expandindo-se no Egito, Caldéia e na Palestina. Nesta mesma época (Antiguidade), Granato (1996) acrescenta que a adoção atendia às pregações religiosas, pois era vista como o último recurso de uma família sem filhos a đar continuidade à sua crença, seu culto.

Na Idade Média, a adoção caiu em declínio por um longo tempo devido à preocupação dos feudos com a consaguinidade e a falta de preocupação com as crianças na época (WEBER, 1998). Após a Revolução Francesa (1789), Napoleão Bonaparte resolveu incluir a adoção no Código Civil ao descobrir que sua esposa era estéril. Porém, as leis eram rígidas e não se preocupava primeiramente com o bem-estar do adotado.

Prado (2006) relata que a primeira lei direcionada à adoção, no Brasil, foi datada de 1828, mas somente o Código Civil de 1916 sistematizou o assunto, impondo que qualquer pessoa sem filhos biológicos e com idade superior a 50 anos podia adotar uma criança através de um contrato com os pais legítimos. Porém, o adotando deveria ser dezoito anos mais velho que o adotado (FONSECA, 2002). A mesma autora acrescenta que só em 1957 o Código Civil foi modificado com um olhar voltado para o bem-estar da criança.

Em 1965, foi criada a "legitimação adotiva" em que era permitida a adoção somente quando a guarda do menor fosse estabelecida antes de ele completar sete anos de idade, os pais biológicos terem destituído o poder ou no caso de criança órfã sem reclamação de um parente há mais de ano (PRADO, 2006).

Surgiu em 13/07/1990 a elaboração e aprovação do Estatuto da Criança e do Adolescente através de um movimento social que possibilitou os mesmos direitos dos filhos legítimos aos filhos adotados (COSTA, 2006).

Segundo Bittencourt (2003), nas primeiras publicações do estatuto a adoção era subdivida em três tipos: a comum (escritura pública regulamentada pelo Código Civil), simples e plena (regulamentadas pelo Código de Menores).

A adoção simples consistia quando um menor de 18 anos em situação irregular convivia com a família adotiva, mas não perdia o contato com a família biológica. 
Além disso, não tinha os mesmos direitos dos filhos legítimos e podia ser anulada. Já na adoção plena, havia o afastamento do adotado (geralmente os que tinham até sete anos de idade) da sua família de origem, passando a ser irrevogável.

Granato (2003) diz que em relação aos requisitos dos adotantes, a idade mínima era de 30 anos para um dos cônjuges, exigia ter cinco anos de matrimônio sem filhos, que poderia ser dispensada na hipótese de esterilidade de um dos cônjuges, desde que provada a estabilidade conjugal.

\section{Adoção X Leis brasileiras atuais}

Com a criação do Novo Código Civil (NCC) em 2002, a adoção simples extingue-se, existindo apenas a classificada como plena, e o instituto da adoção passa a ser regido em conjunto por esse dispositivo legal e o ECA. (ISHIDA, 2006).

Segundo o ECA (2002), homens e mulheres maiores de 18 anos podem adotar (desde que sejam, no mínimo, 16 anos mais velhos que o adotado); independente do seu estado civil, desde que ofereçam um ambiente adequado à criança/adolescente e que não sejam ascendentes ou irmãos do adotando ou que causem algum prejuízo ao adotando.

Pessoas solteiras, viúvas ou que já tenham filhos podem adotar também se tiverem estabilidade econômica e demonstrarem poder oferecer um ambiente adequado ao adotado através de uma avaliação psicossocial realizada pelos profissionais da Vara da Infância e da Juventude.

No caso dos homossexuais, o ECA não impede a adoção desde que não prejudique o bem-estar da criança ou do adolescente e que os adotantes tenham reais condições para cuidar de uma criança. Porém, ainda há poucos casos legalizados no Brasil. Já os divorciados podem adotar conjuntamente se entrarem em acordo com a guarda da criança e horários de visita.

Artigo 41: "Se um dos cônjuges ou concubinos adota
o filho do outro, mantêm-se os vínculos de filiação
entre o adotado e o cônjuge ou concubino do ado-
tante e os respectivos parentes" (ECA, 2002, p.75)

O perfil estabelecido pelo estatuto para os adotados é de que sejam crianças e adolescentes até 18 anos, órfãs, de pais desconhecidos ou falecidos, que concordaram com a adoção do filho ou que foram retiradas da família de origem depois de não terem mais recursos para mantê-la. A adoção de maiores de 18 anos vai depender da assistência do Poder Público e da sentença constitutiva (NCC, 2002). 


\section{A Adoção na atualidade}

O conceito mais atual é o citado pela Associação dos Magistrados Brasileiros (AMB) que criou a Cartilha Adoção Passo a Passo em favor das crianças que vivem em abrigos:

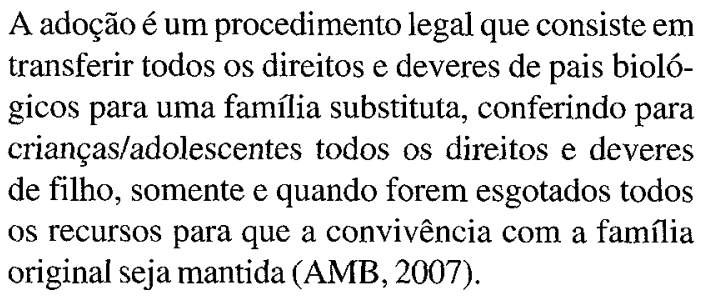

De acordo com a associação supracitada, surgiram novas formas de adoções e a reformulação de alguns conceitos:

Adoção plena: Segundo os autores Bittencourt (2003) e Ishida (2006), esse tipo de adoção passa a ser a única prevista pelo ECA, onde não é mais preciso que a criança se encontre em situação irregular para ser adotada. O prazo de convivência do adotado é determinado pela justiça de acordo com o caso, o registro de nascimento original será cancelado, sendo feito outro com o nome dos adotantes (a partir disso, estes podem mudar o prenome do adotado se assim desejarem); a adoção torna-se irrevogável (mesmo que o adotante venha a falecer, a guarda da criança não volta para a família de origem).

Adoção "à brasileira": ato de registrar uma criança adotiva sem passar pela regulamentação das leis no processo de adoção. Ferreira e Carvalho (2000) dizem que essa prática envolve três situações: parto falso, em que o menor é entregue a uma pessoa inidônea e há falsidade ideológica, quadrilha de tráfico de crianças ou registro ilegal de paternidade.

Adoção pronta: quando a mãe biológica procura a Vara da Infância e da Juventude para legalizar a adoção de seu filho por uma determinada pessoa.

Adoção tardia: consiste na adoção de crianças maiores de dois anos ou adolescentes. Rufino (2003) cita alguns motivos que levam alguns adotantes a querer crianças maiores: por não exigirem os mesmos cuidados de um bebê, por se tratar de casais que já têm filhos adolescentes ou adultos que muitas vezes dão preferência à adoção de maiores que são mais independentes dos pais.

Adoção internacional: É a adoção de crianças e adolescentes por estrangeiros ou brasileiros que moram fora do país, possível somente quando todas as documentações exigidas estejam corretas e o prazo de convivência em território nacional tenha sido cumprido. De acordo com Silveira (2002; 
apud RUFINO, 2003) esse tipo de adoção é muito utilizado quando a criança não é adotada no território nacional, geralmente por ter perfil pouco procurado, como ser mais velha, ter alguma necessidade especial, etc.

Adoções modernas: Freire (2001) refere que esse tipo de adoção equivale às tardias, de crianças com necessidades especiais, entre irmãos, portadoras do vírus HIV e as interraciais. Costa e Ferreira (2007) complementam que essas exigem do adotante uma nova forma de ver e planejar uma família.

A Associação dos Magistrados Brasileiros (AMB), em julho de 2009, divulga que foi aprovada no Senado Federal uma nova lei nacional sobre a adoção que propõe as seguintes regras:

- O tempo de permanência das crianças nos abrigos deverá ser de, no máximo, dois anos e, preferencialmente, em endereço próximo ao da família.

- A cada seis meses, será reavaliada a necessidade de permanência da criança no abrigo, devendo uma equipe multidisciplinar competente decidir pela possibilidade de reintegração familiar ou colocação em família substituta.

- Ampliação do conceito de família com empenho em deixar que o menor fique pelo menos com parentes próximos (avós, tios, etc).

- Exigência de preparação prévia dos pais adotivos e de acompanhamento familiar pós acolhimento em caso de adoção internacional.

- A justiça dará atenção a gestantes ou mães que manifestem interesse em entregar seus filhos para a adoção buscando evitar o abandono de crianças em espaços públicos logo após o nascimento.

-A nova lei impõe ainda a obrigatoriedade de que os irmãos não sejam separados.

No entanto, estas normas devem entrar em vigor no prazo máximo de até três meses após sua aprovação provocando mudanças significativas, como percebemos nos resultados e discussões obtidos nesta pesquisa bibliográfica.

\section{Quadro 1}

Perfil dos adotantes estabelecido através dos artigos (Fonte: SILVA, 2009)

\begin{tabular}{|l|c|}
\hline \multicolumn{2}{|c|}{ Perfil dos adotantes } \\
\hline Idade & Entre 30 e 40 anos \\
\hline Estado civil & Casados \\
\hline Motivo da adoção & Infertilidade \\
\hline Grau de escolaridade & Nível superior \\
\hline Classe social & Média-baixa \\
\hline Cor da pele & Branca \\
\hline
\end{tabular}




\section{Resultados e discussão}

\section{Perfil dos adotantes}

Foram identificados no quadro 1 o perfil dos adotantes do Brasil subdividido em itens: idade, grau de escolaridade, classe social, motivo da adoção, estado civil, cor da pele.

Observa-se que a idade em que mais se pratica a adoção corresponde à fase adulta, pois de acordo com Camarano (2006), nesta etapa da vida há preocupação com o trabalho, o casamento, aquisição da casa própria e planejamento dos filhos.

O estado civil dos adotantes de ser maioria casados pode ser confirmado por outras pesquisas, como a Gondim e colaboradores (2008) realizada em Porto Alegre com um grupo de pessoas que estavam na fila para adoção ou que já tinham adotado uma criança, e a dos juízes Neto e Pachá (2008) lançada no site do Conselho Nacional de Justiça (CNJ), constatando que $90 \%$ dos pretendentes cadastrados são casados ou vivem em união estável.

O motivo predominante da prática de adoção ser devido à infertlidade pode ser confirmado pela experiência clínica de Levinzon (2004), em que a maioria dos pais candidatos justifica ser a infertilidade de um ou do casal. Porém, Penha (2008) diz que não haverá sucesso na adoção nos casos em que o casal não tenha superado essa infertilidade.

Em relação ao grau de escolaridade ser a maioria dos pretendentes à adoção de nível superior e de classe média-baixa pode ser consequiência da condição financeira ser muito considerada no processo, principalmente deverá ter uma profissão que garanta fornecer condições básicas para a sobrevivência da criança (MENEZES, 2007). Além disso, o emocional também influencia.

A maioria dos interessados em adotar crianças e adolescentes são casais brancos, e de acordo com Neto e Pachá (2008), isso justifica o motivo da procura maior para adoção ser por crianças de pele branca.

Quem tem iniciativa em procurar a Vara da Infância e da Juventude é a mulher, demonstrando ser a mais interessada até por questões culturais, pois o exercício da maternidade ainda é desejo principal de grande parte do sexo feminino (LEVY \& CARNEIRO, 2002).

Principais facilidades no processo de adoção no Brasil

O quadro 2 mostra algumas das facilidades no processo de adoção no Brasil citadas nos artigos pesquisados. 


\section{Quadro 2}

Facilidades mais comuns no processo de adoção no Brasil (Fonte: SILVA, 2009)

\begin{tabular}{|l|}
\hline - Lei permite estágio de convivência antes do processo ser concluído. \\
\hline - Há Associações e Grupos de Apoio aos candidatos à adoção no Brasil. \\
\hline - Mudanças na lei que favoreceram mais o bem-estar do adotado. \\
\hline - A adoção tornou-se irrevogável. \\
\hline - Surgimento do cadastro nacional via online. \\
\hline - Conquista de mães adotivas ao direito à licença-maternidade. \\
\hline - A única prioridade para os adotantes é de quem está na frente na fila de espera. \\
\hline
\end{tabular}

O fato de a justiça permitir ao adotante um estágio de convivência com quem pretende adotar antes de concluir o procedimento legal foi criado segundo a lei de 1990, com o objetivo principal de adaptar a convivência do adotando ao novo lar, podendo ser dispensado se referir a uma criança menor de um ano de idade ou se esta já estava com o candidato tempo suficiente para ter tido um vínculo.

As associações e grupos de apoio à adoção no Brasil provaram, através de pesquisas com grupos de pretendentes à adoção, os vários benefícios que traz aos adotantes, dentre eles, Santos (2004) cita, principalmente, as mudanças de posicionamento e papéis assumidos por candidatos, além do aumento das possibilidades de mudar de idéia quanto ao perfil convencional das crianças procuradas para adoção. Porém, esses grupos de apoio ainda são em pequeno número em relação ao contigente de candidatos à adoção no país.

Já sobre a preocupação, mais com o bem-estar do adotado do que com os interesses do adulto, começou a surgir no Código Civil de 1957, mas concretizou-se com o Estatuto da Criança e do Adolescente (Art. 43) quando o processo tornou-se irrevogável, ou seja, não havendo como desistir do processo após a publicação da sentença constitutiva. De acordo com Diniz (2002), mesmo que ocorra o falecimento do adotante, a família biológica não terá o direito novamente sobre o adotado.

De acordo com o Conselho Nacional da Justiça (CNJ) o cadastro nacional da adoção foi criado em 2008 com os objetivos principais de ajudar os juízes das Varas da Infância e da Juventude do Brasil a ter maior controle sobre os processos de adoção, agilizar os processos cada vez mais e possibilitar a inserção de políticas públicas.

Um outro quesito importante, no processo de adoção, citado por um dos artigos pesquisados é a conquista de mães adotivas ao direito à licença-maternidade no ano de 2002, concedido pela justiça pelo fato de que a lei prevê desde a Carta Magna, 
o bom desenvolvimento físico e psicológico de uma criança (independente de ser adotiva ou não) e, para isso acontecer, é indispensável a presença da mãe (SIQUEIRA, 2009).

Em relação à prioridades para adotar, o motivo para tal ato, ter filhos ou não e outros itens, não são características que dão prioridade na fila de espera dos adotantes.

Principais dificuldades no processo de adoção no Brasil

O quadro 3 representa as principais dificuldades no processo de adoção no Brasil, com as respectivas discussões.

\section{Quadro 3}

Dificuldades mais comuns no processo de adoção no Brasil (Fonte: SLLA, 2009)

- Pouca pesquisa científica.

- O cadastro nacional ainda não foi atualizado em todos os estados brasileiros.

- Preconceitos/Mitos.

- Desproporção entre $n^{\circ}$ de crianças e adolescentes disponíveis para adotar e candidatos à adoção.

- Lei dificulta adoção por homossexuais.

- Crianças com até 3 anos de idade são as que conseguem ser adotadas na maioria das vezes.

- Burocracias no processo.

- Exigência no perfil das crianças não contigente ao das que estão disponíveis para a adoção.

A quantidade de pesquisas científicas publicadas sobre o tema adoção tem aumentado nos últimos oito anos, porém ainda está escassa a pesquisa especificamente sobre o perfil dos adotantes. Atualmente, o cadastro nacional ainda está em fase de construção, mas quando estiver disponível em todo o Brasil, estes dados serão mais facilmente coletados.

Na maioria dos artigos, tese e dissertação lidos fala-se do preconceito e mitos que giram em torno do processo de adoção em si e dos principais envolvidos (crianças e/ou adolescentes e adotantes). Dentre eles, destaca-se o preconceito racial contra as crianças que estão à espera de adoção e não são de 
pele clara ou da sociedade que discrimina pessoas que adotam uma criança com cor da pele diferente da sua; a adoção por homossexuais que sofrem com a homofobia e a ausência de igualdade de direitos na lei; preconceito na escola sofrido pelos pais adotivos e pelas próprias crianças/adolescentes.

Já em relação aos mitos, os mais comuns são os citados por Schettini (2007) como o medo da hereditariedade e de os filhos adotivos serem vistos como problemáticos, rebeldes, mal agradecidos com a família adotiva, não superando o trauma de terem sido abandonados.

Dados divulgados em vários locais, especificamente pela Agência Brasil e Associação dos Magistrados Brasileiros, revelam que há aproximadamente no país 22 mil candidatos cadastrados à prática de adoção e duas mil crianças à espera para ser adotada, ou seja, a quantidade de crianças e adolescentes disponíveis para a adoção são desproporcionais ao número de candidatos a realizar o processo.

O fato de a lei brasileira dificultar a adoção realizada por homossexuais é discutido em vários artigos científicos e a maioria dos autores é a favor de legalizar este ato, pois o conceito de família está se ampliando e, no Código civil, não é citado de forma clara se influencia, no processo, a orientação sexual dos adotantes.

Além disso, Monteiro (2006) diz que a harmonia do ambiente familiar não é influenciado pela homossexualidade do adotante, desde que este ofereça um lar estruturado para a criança adotiva.

O cadastro nacional ainda deve ser atualizado em vários locais do Brasil, podendo ser compreendido pelo fato de o sistema ter sido lançado há pouco tempo.

De acordo com o Conselho Nacional de Justiça, em 2008, a maioria dos pretendentes cadastrados é de São Paulo e Paraná, enquanto que as crianças cadastradas são, em sua maioria, do Distrito Federal, São Paulo e Paraná.

Grande parte dos candidatos à adoção procura por um mesmo perfil de criança: do sexo feminino e saudáveis, com até 2 ou 3 anos de idade, cor da pele branca e cabelos lisos.

Sendo assim, as que possuem mais de três anos de idade e adolescentes acabam permanecendo nas instituições, ou seja, a adoção tardia é muito pouco realizada no nosso país.

\section{Conclusão}

O presente trabalho apresentou o perfil dos adotantes brasileiros nos últimos seis anos e as principais dificuldades e facilidades no processo de adoção no Brasil ao longo dos anos. 
Foi possível observar que essas características citadas anteriormente modificam-se à medida que vão sendo aprovadas novas leis, diversificando culturas e outros aspectos, pois vão permitindo que pessoas com diversos perfis adotem uma criança ou adolescente. Acredita-se que as principais dificuldades e facilidades no processo terão outros enfoques daqui a poucos anos.

É necessário realizar mais pesquisas sobre os adotantes brasileiros após a atualização dos cadastros nacionais via online em todo o país, pois os artigos encontrados para a realização deste trabalho são em sua maioria, de pesquisas dos mesmos estados (Distrito Federal, por exemplo) e há uma variedade do perfil de adotantes nas diferentes regiões brasileiras.

Os estudos apresentados constatam também que a desinformação é a principal responsável por preconceitos e mitos ainda muito presentes em todo o país.

Sendo assim, considera-se o tema adoção amplo e polêmico, necessitando de maiores discussões também na mídia brasileira para que assim as pessoas possam ser mais incentivadas e preparadas para o processo adotivo.

\section{Considerações finais}

A maioria dos estudos encontrados sobre adoção é dos cursos de Direito, Psicologia e Serviço Social, pois são os principais envolvidos nesse processo. Porém, o tema é mais abrangente do que parece, e com estas novas leis que entrarão em vigor, no final de 2009 , outros profissionais poderão contribuir para que antes que uma adoção seja concedida legalmente, tenha sido feita uma melhor investigação e preparação, tanto dos que pretendem adotar quanto dos que serão adotados.

Dentre esses profissionais que farão parte da equipe multidisciplinar que avaliará o que for melhor para a criança e/ou adolescente, o Terapeuta Ocupacional pode estar inserido por ser profissional da área da saúde que avalia as necessidades, problemas e preocupações ocupacionais do sujeito de maneira biopsicossocial, através de atividades.

Além disso, o profissional citado também tem capacidade de montar e coordenar esses grupos de apoio, utilizando a análise de atividades para facilitar o processo grupal e saber conduzi-los, transmitindo as informações sobre o processo de adoção de maneira mais lúdica.

Também é capacitado a participar efetivamente da avaliação do abrigamento (se o ambiente está de acordo para o bom desenvolvimento da criança), avaliar se os candidatos para adoção estão aptos ou não e fazer o acompanhamento durante o estágio de convivência do adotante e adotado. 
Consequentemente, o lar em que a criança e/ou adolescente esperarão para serem adotados serão muito mais bem preparado para recebê-los, diminuindo as consequiências negativas após a adoção ter sido efetivada, vindas principalmente do preconceito e dos mitos que não foram bem trabalhados com os adotantes antes do processo.

\section{Agradecimentos}

Agradeço aos meus pais pela dedicação, apoio e ao curso de Terapia Ocupacional da Universidade de Uberaba (UNIUBE) pelos conhecimentos transmitidos importantes para a minha formação.

\section{Referências bibliográficas}

AMIM, I D. \& MENANDRO, P.R.M. Preferências por características do futuro filho adotivo manifestada por pretendentes à adoção. Interação em Psicologia, v.2, n.11, 2007.

ARAUJO, L.F. \& OLIVEIRA, J.S.C. A adoção de crianças no contexto da homoparentalidade. Arquivos Brasileiros de Psicologia, v.60, n.3, 2008.

ASSUNÇÃO, E.R. A extensão da licença-maternidade à adotante em face do princípio da igualdade. Jus Navigandi, Teresina, n.1424, 2007.

BITTENCOURT, E.M. Família. Campinas: Millennium, 2003. 305 p.

BOCHNIA, S.F. Da adoção: categorias, paradigmas e práticas do direito de família. Dissertação de Mestrado. Curso de Pós-Graduação em Direito, Universidade Federal do Paraná. Curitiba/PR, 2008.

CALDAS, R. A possibilidade de pessoas de sexo distintos adotarem independente da condição de conjugues ou companheiros em contraposição a legitimidade prevista no código civil para tal instituto. Buscalegis, Santa Catarina, 2006.

CAMARANO, A.A. Considerações finais: Transição para a vida adulta ou vida adulta em transição. Pp. 319-29, 2006.

Cartilha Adoção Passo a Passo. Disponível em: <http://www.amb.com.br/>. Acesso: 8 de Setembro/2008.

COIMBRA, J.C. A demanda nos processos de habilitação para adoção e a função dos dispositivos judiciais. Estudos e Pesquisas em Psicologia, 5(2), 2005. 
COMIN, F. \& SANTOS, M.A. Aprender a viver é o viver mesmo: o aprendizado a partir do outro em um grupo de pais candidatos à adoção. Vínculo, 5(2), São Paulo, 2008.

COSTA, L.F. A avaliação psicossocial no contexto da adoção. Psicologia: teoria e pesquisa, Brasília, 19(3). 2003.

COSTA, M.J.A. Direito das obrigações. $9^{a}$ Edição. Coimbra: Almedina, 2006.

COSTA, N. R.A. \& FERREIRA, M.C.R. Tornar-se pai e mãe em um processo de adoção tardia. Psicologia: reflexão e crítica, v. 20, n. 3, 2007.

DINIZ, M. H. Dicionário jurídico. São Paulo: Saraiva, 1998.

DINIZ, M H. Curso de direito civil brasileiro: direito de família. $18^{a}$ Edição. São Paulo: Saraiva, 2002.

Estatuto da Criança do Adolescente. Disponível em: <http://www.planalto.gov.br $>$. Acesso: 2 de Setembro/2008.

FONSECA, C. Da circulação de crianças à adoção internacional: questões de pertencimento e posse. Buscalegis, Santa Catarina, 2006.

FERREIRA, M.R. \& CARVALHO, S.R. Primeiro guia de adoção de crianças $e$ adolescentes do Brasil. São Paulo: Winners, 2000.

FONSECA, C. Caminhos da adoção. São Paulo: Cortez, 2002.

FREIRE, F. Abandono e adoção III: contribuições para uma cultura da adoção. Curitiba: Terra dos Homens, 2001.

FUTINO, R. S; MARTINS, S. Adoção por homossexuais: uma nova configuração familiar sob os olhares da psicologia e do direito. Aletheia, Canoas, n. 24, 2006.

GAGNO, A. P; WEBER, L. N. D et al. A adoção na mídia: revisão de literatura nacional e internacional, São Paulo, 2003.

GONDIM, A.K.; CRISPIM, C.S.; FERNANDES, F.H.T; ROSENDO, J.C; BRITO, T.M.C; OLIVEIRA, U.B. \& NAKANO, T.C. Motivação dos pais para a prática da adoção. Boletim de Psicologia, v.58, n.129, 2008.

GRANATO, E.F.R. Adoção: doutrina e prática. Curitiba: Juruá, 2003.

GUARESCHI, N.M.F. et al. Quem está apto? A prática de adoção e marcadores identitários. Aletheia, Rio Grande do Sul, n. 25, 2007.

ISHIDA, V.K. Estatuto da criança e do adolescente. São Paulo: Atlas, 2006. 
LEVINZON, G.K. Adoção. São Paulo: Casa do Psicólogo, 2004.

LEVY, L; CARNEIRO, T. Famílias monoparentais femininas: um estudo sobre a motivação de mulheres que adotam. Interação em Psicologia, v.2, n. 6. 2002.

MARIANO, F.N. \& FERREIRA, M.C.R. Que perfil da família biológica e adotante e da criança adotada revelam os processos judiciais? Psicologia: reflexão e crítica, v.1, n.11, 2007.

MARIO, C. A adoção tardia no Brasil: desafios e perspectivas para o cuidado com crianças e adolescentes. Simpósio Internacional do Adolescente, São Paulo, 2005.

MENEZES, L. Adoção: o amor acima de qualquer preconceito. 2007.

MONTEIRO, S.W. B. Possibilidade de adoção por casal homossexual. 2006.

NETO, F. O. \& PACHÁ, A.O. Cadastro nacional de adoção: primeiros resultados.2008.

PADOVEZE, A.A.L. \& PETINARI, S.C. Adoção de crianças por homossexuais. Anuário da produção de iniciação científica discente, São Paulo, v. 11, n. 12, 2008.

PENHA, A.R.B. Adoção por casais homoafetivos. Unitoledo, Presidente Prudente, 2008.

PURETZ, A. \& LUIZ, D. Adoção tardia: desafios e perspectivas na sociedade contemporânea. Emancipação, Ponta Grossa, v.7, n.2, 2007.

PRADO, M.R. O processo de adoção no Brasil, Unitoledo, Presidente Prudente, 2006.

REPPOLD, C.T. \& HUTZ, C.S. Reflexão social, controle percebido e motivações à adoção: características psicossociais das mães adotivas. Estudos de Psicologia, v.1, n.8, 2003.

RUFINO, S.S. Nos elos de uma filiação multirracial: A adoção inter-racial nos limiares da educação intercultural, 2003.

SANTOS, M.A. Percepções de pais acerca de uma experiência em grupo de apoio a adotantes: uma construção sistêmica, Spagesp, Ribeirão Preto, v.5, n.5, 2004.

SCHETTINI, S.S.M; AMAZONAS, M.C.L. \& DIAS, C.M.S. Famílias adotivas: identidade e diferença. Psicologia em estudo, Maringá, v.11, n. 2, 2006. 
SCHETTINI, S.S.M. Filhos por adoção: Um estudo sobre o seu processo educativo em famílias com e sem filhos biológicos. Dissertação de Mestrado em Psicologia Clínica, Universidade Católica de Pernambuco, 2007.

SCORSOLINI-COMIN, F; AMATO, L.M. \& SANTOS, M.C. Grupos de apoio para casais pretendentes à adoção: a espera compartilhada do futuro. Spagesp, Ribeirão Preto, v.7, n.2, 2006.

SILVA, A.P. Encontros e Desencontros na adoção- considerações a partir de um caso clínico. Dissertação de Mestrado. Curso de Pós-Graduação em Psicanálise, Universidade Estadual do Rio de Janeiro, 2007.

SILVEIRA, A.M. Particularidades da Adoção: a questão da etnia. 2002.Dissertação (Mestrado em Serviço Social) Pontifícia Universidade Católica de São Paulo, PUC. São Paulo.

SIQUEIRA, L.F.T. Licença-maternidade: direito constitucional da mãe adotiva. Disponível em: <http://www.buscalegis.ufsc.br/revistas/index.php/buscalegis/article $>$. Agosto/2009.

VALIKO, F.A.B. Adoção à luz do estatuto da criança e do adolescente e do novo código civil . Buscalegis, Santa Catarina, 2003.

WEBER, L.N. Laços de ternura: pesquisa e histórias de adoção. Curitiba: Santa Mônica, 1998. 